\title{
Influence of pulse electrodeposition parameters on microhardness, grain size and surface morphology of $\mathrm{Ni}-\mathrm{Co} / \mathrm{SiO}_{2}$ nanocomposite coating
}

\author{
SIAVASH IMANIAN GHAZANLOU ${ }^{1, *}$, ALI SHOKUHFAR ${ }^{1}$, SHIVA NAVAZANI ${ }^{1}$ \\ and REZVAN YAVARI ${ }^{2}$ \\ ${ }^{1}$ Advanced Materials and Nanotechnology Research Laboratory, Faculty of Materials \\ Science and Engineering, K. N. Toosi University of Technology, Tehran 1969764499, Iran \\ ${ }^{2}$ Faculty of Materials and Metallurgy Engineering, Semnan 35131-19111, Iran
}

MS received 3 November 2015; accepted 17 March 2016

\begin{abstract}
Ni}-\mathrm{Co} / \mathrm{SiO}_{2}$ nanocomposite coatings and $\mathrm{Ni}-\mathrm{Co}$ alloy coatings were prepared on steel substrate using direct and pulse electrodeposition methods. X-ray diffraction (XRD), field emission scanning electron microscope (FESEM), X-ray map and energy dispersive X-ray spectroscopy (EDX) were employed to investigate the phase structure, surface morphology, and elemental analysis of coatings, respectively. In high discharge rates, the surface morphology was rough, disordered and gross globular; on the contrary, in the low rates, it was smoother, more ordered and fine globular. Also, effect of electrodeposition parameters such as average current density, pulse frequency and duty cycle on the microhardness and grain size of nanocomposite coatings that produced through the pulse current electrodeposition method have been investigated. By amplifying both duty cycles up to $50 \%$ and average current density from 2 to $6 \mathrm{~A} \mathrm{dm}^{-2}$, microhardness increased, while the grain size decreased. But when duty cycle mounted on more than $50 \%$ and the average current density went up to $8 \mathrm{~A} \mathrm{dm}^{-2}$, microhardness lessened, while the grain size rose. The optimum value for pulse frequency was about $25 \mathrm{~Hz}$. Results showed that microhardness of nanocomposite coatings which were produced by pulse current method was higher than that of produced by direct current method.
\end{abstract}

Keywords. Nanocomposite coating; electrodeposition; average current density; pulse frequency; duty cycle.

\section{Introduction}

One of the best methods to produce nanostructure coatings is electrodeposition method, in which discharge is performed on the cathode. Nucleation on the cathode is affected by different agents such as crystal structure of the substrate, surface free energy, adhesion energy, crystal orientation of electrode surface and crystallographic lattice of the crystalline depositsubstrate [1].

For the first time, nanostructure metals and alloys were prepared by blowing inert metallic gas on a cold substrate in which fast gas condensation and fast nucleation occurred; thus, nanometric grain sizes were obtained. Among other methods, plasma, physical and chemical vapour deposition, electrochemical deposition, fast solidification, mechanical alloying and sever plastic deformation can be numerated. Nanostructures prepared by electrodeposition, however, have been widely investigated since 1990 [1].

Recently, studies are done on nanocomposite coatings prepared by electrodeposition method. These coatings due to their high corrosion and wear resistance, have a wide range of applications in automobile industry, engines and casting modules [2]. Theoretical model for electrodeposition process of metal matrix composite can be delineated into

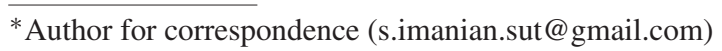

four stages: (1) surface charge formation on the particle surface of the suspension, (2) mass transfer of particles from the suspension onto the cathode surface, (3) the interaction between cathode surface and particles and (4) nanoparticles entrapped in the growing metal layers [3].

Electrochemical deposition can be achieved by direct current (DC), pulse current (PC) [4], pulse reverse current (PRC) and pulse potentiostatic deposition [3]. In DC method, the current remains stable with respect to time, while in PC method, the current at $T_{\mathrm{ON}}(\mathrm{ON}$ time) has a certain value, but at $T_{\mathrm{OFF}}$ (OFF time) it is zero [4]. In PRC method, the current has a positive value at $T_{\mathrm{ON}}$ and a negative value at $T_{\mathrm{OFF}}$ [3].

It should be mentioned that there are two important parameters in pulse current method: pulse frequency and duty cycle. Pulse frequency is obtained from the following equation:

$$
F=1 /\left(T_{\mathrm{ON}}+T_{\mathrm{OFF}}\right) .
$$

While the duty cycle can be obtained from:

$$
\gamma=T_{\mathrm{ON}} /\left(T_{\mathrm{ON}}+T_{\mathrm{OFF}}\right) .
$$

In DC method, the duty cycle is always $100 \%$ [5].

Different studies demonstrated that by increasing the current density, microhardness of coated layer decreases [2,6-19]. Accordingly, current density has an optimum value for nanocomposite coating in electrodeposition process. Yang and 
Cheng [5] reported that in manufacturing $\mathrm{Ni}-\mathrm{Co} / \mathrm{SiC}$ nanocomposite coating, by increasing the pulse frequency and reducing duty cycle, $\mathrm{SiC}$ content in the coating increased, thereby the microhardness of coated film increased. Microhardness of coating which was prepared in PRC method is more than that of in PC method. Also in PC method, microhardness of prepared coating is more than that of in DC method [4].

Arunsunai Kumar et al [20] concluded that in generating $\mathrm{Ni}-\mathrm{W} / \mathrm{TiO}_{2}$ coating, micro hardness of prepared coating in PC method was more than that in DC method. Shahri and Allahkaram [8] reported that in preparing $\mathrm{Co} / \mathrm{BN}$ nanocomposite coating, by increasing the current density to a specific value, grain size decreased which is due to the increase in nucleation rate. But further increasing the current density, because of changes in both surface energy and growth mechanisms in the presence of hydrogen, grain size increased. Yang and Cheng [5] reported that increasing the pulse frequency and decreasing the duty cycle led to increase in the amount of particles in the $\mathrm{Ni}-\mathrm{Co} / \mathrm{SiC}$ composite coating, thereby grain size reduces. Many studies have concentrated on the effective parameters in preparing nickel-based nanocomposite coatings.

During the preparation of $\mathrm{Ni} / \mathrm{CeO}_{2}$ nanocomposite coating, Sen et al [21] found that by increasing the temperature, kinetic and thermodynamic driving forces affect the final grain size of $\mathrm{Ni} / \mathrm{CeO}_{2}$ nanocomposite coating. In another study, effect of uniform distribution on the nickel matrix was evaluated and it was concluded that $\mathrm{TiO}_{2}$ nanoparticles could restrain the growth of nickel grains [11]. Another study concluded that adding $\mathrm{SiC}$ nanoparticles could limit crystalline growth of deposited zinc metal [14]. Effect of adding SiC nanoparticles was also investigated in another study [22]. It was found that the nanoparticles by reducing the mobility of grain boundaries of nickel (pinning effect), led to reduction of the grain growth of nickel.

Arab Juneghani et al [16] reported that the addition of $\mathrm{SiC}$ nanoparticles led to increase in the number of nucleation sites in the matrix and thereby the grain size decreased. Also, the addition of $\mathrm{Si}_{3} \mathrm{~N}_{4}$ nanoparticles into the copper matrix, leads to decrease in the grain size of prepared nanocomposite coating $[17,23]$. In another research, grain size of $\mathrm{Ni}-\mathrm{Fe}_{2} \mathrm{O}_{3}$ nanocomposite coating was finer than pure nickel coating [24]. Addition of nanoparticles to the plating bath and their entrapment in the nickel matrix caused to reduce the grain size of nanocomposite coating [7,20,25-35]. Finally, during preparing $\mathrm{Ni}-\mathrm{W}-\mathrm{B} / \mathrm{CeO}_{2}$ nanocomposite coating, Wang Junli et al [36] concluded that decreasing duty cycle from 75 to $10 \%$ led to decrease the grain size.

No study has yet focussed on $\mathrm{Ni}-\mathrm{Co} / \mathrm{SiO}_{2}$ nanocomposite coating prepared by electrodeposition method. In the present work, for the first time, Ni-Co nanocomposite coating reinforced by $\mathrm{SiO}_{2}$ nanoparticles was processed by electrodeposition method and effects of electrodeposition parameters such as average current density, pulse frequency and duty cycle on microhardness and grain size of nanocomposite coating were investigated. There were insufficient reports about effect of current density, pulse frequency and duty cycle on the microhardness and grain size of the coating. Analysis of previous works were merely an observation and are reported. According to the nature of these phenomena, comprehensive and novel analyses are presented here. Also, the effects of electrdeposition methods (PC and DC), current density, pulse frequency and duty cycle on the surface morphology of coatings have never been investigated before.

\section{Materials and methods}

$\mathrm{Ni}-\mathrm{Co}$ coating and $\mathrm{Ni}-\mathrm{Co} / \mathrm{SiO}_{2}$ nanocomposite coating were deposited on the substrate of a $1 \times 1 \mathrm{~cm}$ mild carbon steel (with $0.43 \%$ carbon) by direct and pulse current methods. The carbon steel substrates as cathode were polished by emery paper (400, 600 and 1000) prior to the electrodeposition process and then dipped in ethanol and $10 \% \mathrm{HCl}$ for 2 min and $15 \mathrm{~s}$, respectively. Finally, the substrates were washed in distilled water. A sheet of pure $1 \times 1 \mathrm{~cm}$ nickel was used as anode.

Working surface area of all the samples was 1 and $3 \mathrm{~cm}^{2}$ for cathode and anode, respectively. Pulse and direct current were produced by a power supply. The electrolyte was agitated via a digital magnetic stirrer with a hot plate. Coating bath volume was $100 \mathrm{ml}$ and the length of magnet was $2 \mathrm{~cm}$. As shown in table 1, Watt's bath composition was used to prepare the electrolyte for coating. In this work, $20 \mathrm{~nm} \mathrm{SiO}{ }_{2}$ nanoparticles (99.5\% Merck) were used as reinforcement. Eleven specimens were coated by $\mathrm{Ni}-\mathrm{Co} / \mathrm{SiO}_{2}$ nanocomposite. Also two Ni-Co alloy-coated samples were prepared.

Table 2 reports the electrodeposition parameters for preparing the specimens. Variations of current density from 2 to 4 and 6 to $8 \mathrm{~A} \mathrm{dm}^{-2}$ are applied on specimens 1-4.

Samples 5, 2, 6 and 7 show variations of pulse frequency from 5 to 10 and 25 to $100 \mathrm{~Hz}$. Specimens 8, 9, 2 and $10 \mathrm{rep}-$ resent variations of duty cycles from 30 to 40 and 50 to $60 \%$.

Conditions for preparing the samples are as follows: $50^{\circ} \mathrm{C}$ electrolyte temperature, $300 \mathrm{rpm}$ stirring rate, $4.3 \mathrm{pH}$ and $90 \mathrm{~min}$ coating time. For all the electrolytes, $50 \mathrm{ml}$ distilled water with $\mathrm{SiO}_{2}$ nanoparticles and sodium dodecylsulphate (98\% Scharlou) were primarily added to the beaker and agitated for $24 \mathrm{~h}$ at a stirring rate of $1200 \mathrm{rpm}$. Watt's materials and distilled water were respectively added to the beaker until water volume reached to $100 \mathrm{ml}$. When the coating solution was prepared, temperature of magnetic stirrer plate was increased until the solution temperature reached to $50^{\circ} \mathrm{C}$.

Table 1. Composition of the plating bath.

\begin{tabular}{lc}
\hline Material & Concentration $\left(\mathrm{g} \mathrm{l}^{-1}\right)$ \\
\hline $\mathrm{NiSO}_{4} \cdot 6 \mathrm{H}_{2} \mathrm{O}$ & 220 \\
$\mathrm{NiCl}_{2} \cdot 6 \mathrm{H}_{2} \mathrm{O}$ & 40 \\
$\mathrm{H}_{3} \mathrm{BO}_{3}$ & 30 \\
$\mathrm{CoSO}_{4} \cdot 7 \mathrm{H}_{2} \mathrm{O}$ & 25 \\
nano-SiO & \\
Sodium dodecylsulphate & 15 \\
& 0.3 \\
\hline
\end{tabular}


Table 2. Electrodeposition parameters for preparing the specimens.

\begin{tabular}{lcccr}
\hline Specimen number & $\begin{array}{c}\text { Current } \\
\text { type }\end{array}$ & $\begin{array}{c}\text { Current } \\
\text { density } \\
\left(\mathrm{A} \mathrm{dm}{ }^{-2}\right)\end{array}$ & $\begin{array}{c}\text { Pulse } \\
\text { frequency } \\
(\mathrm{Hz})\end{array}$ & $\begin{array}{r}\text { Duty } \\
\text { cycle } \\
(\%)\end{array}$ \\
\hline$\left(\mathrm{Ni}-\mathrm{Co} / \mathrm{SiO}_{2}\right), 1$ & Pulse & 2 & 10 & 50 \\
$\left(\mathrm{Ni}-\mathrm{Co} / \mathrm{SiO}_{2}\right), 2$ & Pulse & 4 & 10 & 50 \\
$\left(\mathrm{Ni}-\mathrm{Co} / \mathrm{SiO}_{2}\right), 3$ & Pulse & 6 & 10 & 50 \\
$\left(\mathrm{Ni}-\mathrm{Co} / \mathrm{SiO}_{2}\right), 4$ & Pulse & 8 & 10 & 50 \\
$\left(\mathrm{Ni}-\mathrm{Co} / \mathrm{SiO}_{2}\right), 5$ & Pulse & 4 & 5 & 50 \\
$\left(\mathrm{Ni}-\mathrm{Co} / \mathrm{SiO}_{2}\right), 6$ & Pulse & 4 & 25 & 50 \\
$\left(\mathrm{Ni}-\mathrm{Co} / \mathrm{SiO}_{2}\right), 7$ & Pulse & 4 & 100 & 50 \\
$\left(\mathrm{Ni}-\mathrm{Co} / \mathrm{SiO}_{2}\right), 8$ & Pulse & 4 & 10 & 30 \\
$\left(\mathrm{Ni}-\mathrm{Co} / \mathrm{SiO}_{2}\right), 9$ & Pulse & 4 & 10 & 40 \\
$\left(\mathrm{Ni}-\mathrm{Co} / \mathrm{SiO}_{2}\right), 10$ & Pulse & 4 & 10 & 60 \\
$\left(\mathrm{Ni}-\mathrm{Co} / \mathrm{SiO}_{2}\right), 11$ & Direct & 4 & - & 100 \\
$(\mathrm{Ni}-\mathrm{Co}), 12$ & Pulse & 4 & 10 & 50 \\
$(\mathrm{Ni}-\mathrm{Co}), 13$ & Direct & 4 & - & 100 \\
\hline
\end{tabular}

Electrolyte metallic salts such as $\mathrm{NiSO}_{4} \cdot 6 \mathrm{H}_{2} \mathrm{O}$ and $\mathrm{CoSO}_{4} \cdot 7 \mathrm{H}_{2} \mathrm{O}$ were dissolved in water and subsequently dissociated into positive and negative ions. Because of high surface activity of nanoparticles, positive ions $\mathrm{CNi}^{2+}$ and $\mathrm{Co}^{2+}$ ) stuck on the surface of nanoparticles and formed an positive ionic cloud around them. This led to the attraction of nanoparticles by cathode surface, so that they entrapped into the matrix and nanocomposite was formed.

Owing to characterization, Buhler microhardness device was employed to determine Vickers microhardness. Tests were done under vertical load of $100 \mathrm{~g}$ and loading time of $10 \mathrm{~s}$. The microhardness of each sample was measured 10 times and the average value was chosen as microhardness of specimen. To investigate the phase structure of the specimens, $\mathrm{X}$-ray diffraction (stoe-stadi-mp) with a $\mathrm{CuK} \alpha$ radiation of $0.154 \mathrm{~nm}$ wave length was used. Moreover, surface morpho logy, elemental analysis and elemental distribution were investigated through field emission scanning electron microscope (FESEM MIRA 3 TESCAN).

Energy dispersive X-ray spectroscopy (EDX) and X-ray map (which attached to the FESEM) were employed to investigate elemental analysis and elemental distribution of coatings, respectively. Grain size of $\mathrm{Ni}-\mathrm{Co} / \mathrm{SiO}_{2}$ nanocomposite coating was calculated through famous Scherrar's equation (equation (3)):

$$
t=0.9 \lambda / B \cos \theta_{\mathrm{B}},
$$

where $t$ is the grain size in nanometers, $\lambda$ the wavelength $(0.154 \mathrm{~nm})$ of $\mathrm{CuK} \alpha$ radiation, $B$ the full width half maximum (FWHM) at $2 \theta_{\mathrm{B}}$ radians and $\theta_{\mathrm{B}}$ the Bragg's angle [37].

\section{Results and discussion}

\subsection{Phase structure}

Figure 1 illustrates X-ray diffraction patterns for 12 specimens obtained by changing current density, pulse frequency

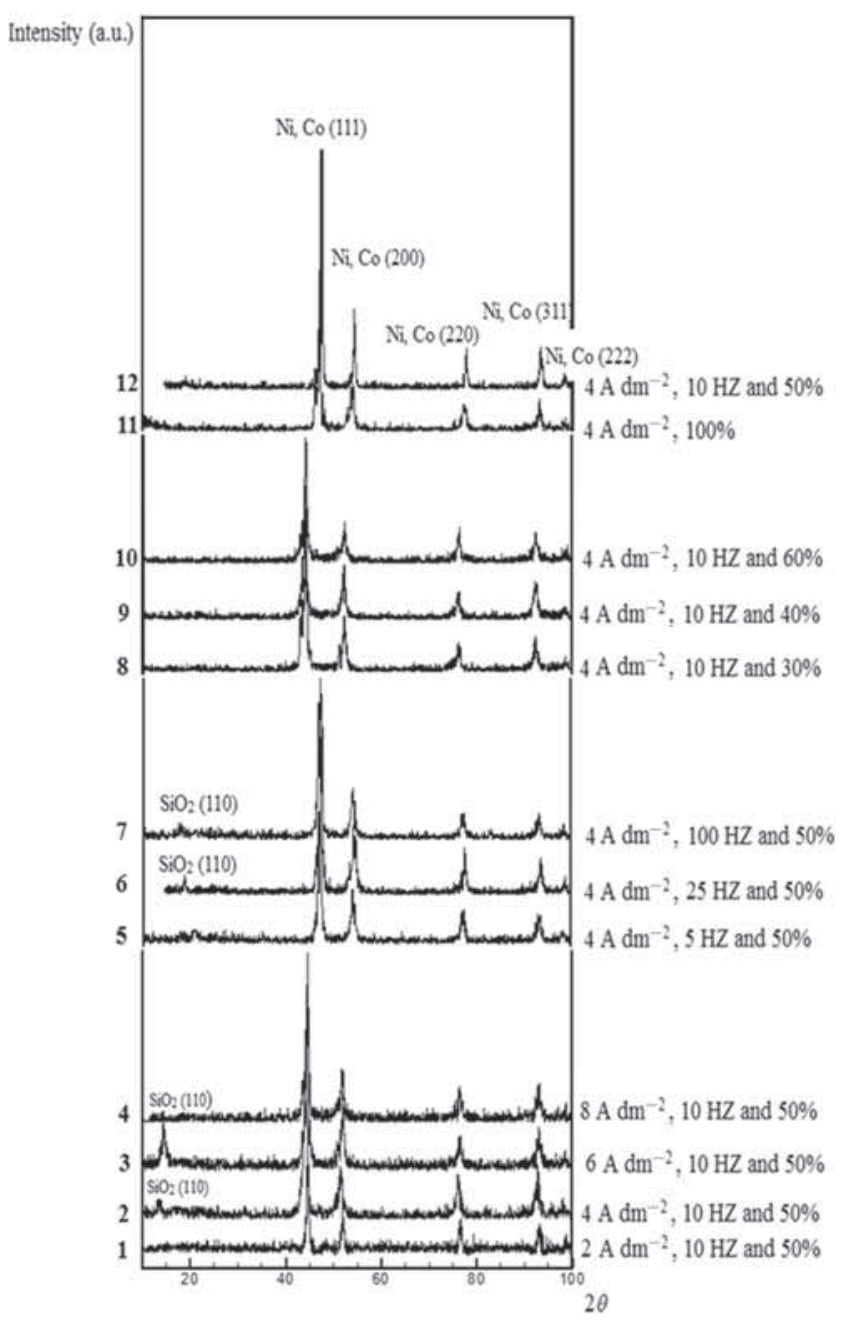

Figure 1. X-ray diffraction patterns in different electrodeposition conditions of coatings extracted from table 2 .

and duty cycle for $\mathrm{Ni}-\mathrm{Co} / \mathrm{SiO}_{2}$ nanocomposite coatings and $\mathrm{Ni}-\mathrm{Co}$ alloy coatings prepared by pulse current electrodeposition method. In this figure, the number of XRD patterns are related to the number of samples in table 2. Production conditions have been described in table 2 . Peaks related to nickel-cobalt alloy were observed in $2 \theta=45,51.5,76.3$, 93 and $98.5^{\circ}$. Moreover, $\mathrm{SiO}_{2}$-related peak (plane of (110) in $2 \theta=14^{\circ}$ ) could be seen in just four of the specimens with higher microhardness and abundant amount of entrapped $\mathrm{SiO}_{2}$ nanoparticles.

In these patterns, peaks of nickel-cobalt alloy and their related plane can be observed. Related ranges of nickelcobalt alloy peaks were as follows: $\left(40-50^{\circ}\right),\left(50-60^{\circ}\right),(70-$ $\left.80^{\circ}\right)$ and $\left(90-100^{\circ}\right)$. All the specimens exhibited the growth orientation of crystal face (111). Because plane (111) had the most diffraction intensity. The addition of $\mathrm{SiO}_{2}$ nanoparticles had no effect on the intensity.

In another research to prepare $\mathrm{Ni}-\mathrm{Co}-\mathrm{TiO}_{2}$ nanocomposite coating by pulse electrodeposition method on a mild steel substrate it was reported that for $\mathrm{Ni}-\mathrm{Co}$ without $\mathrm{TiO}_{2}$ nanoparticles, plane (200) (with maximum intensity) was 
dominant for crystal growth orientation, but by adding $2.5 \mathrm{wt} \%$ of $\mathrm{TiO}_{2}$ nanoparticles into the coating, the orientation of the composite coatings changed from (200) to (111) (with maximum intensity) [35].

Differences between the researches are maybe due to different electrodeposition parameters such as temperature, stirring rate, plating time, $\mathrm{pH}$, type of nanoparticles and chemical composition of plating bath. All of these parameters are very prominent and could impress the coating process. Other crystal planes related to nickel-cobalt alloy were (200), (220), (311) and (222).

If the wt\% of some phases in a sample is less than the critical value (it depends on accuracy of XRD device, type of phase and matrix), XRD device cannot show their related peaks, or the intensity of the peaks will be too low to see and can be ignored. Maybe because of the mentioned reasons, in some specimens, amount of $\mathrm{SiO}_{2}$ nanoparticles was too low and $\mathrm{SiO}_{2}$-related peak had been disappeared. With regards to XRD analysis and diagrams of microhardness of coatings, it becomes clear that specimen with the sharpest $\mathrm{SiO}_{2}$ peak (see figure 1, specimens number 3 ), has the most microhardness, too (see figure $5 \mathrm{~b}$, microhardness corresponds to the current density of $6 \mathrm{~A} \mathrm{dm}^{-2}$ ). Also, it has the sharpest $\mathrm{SiO}_{2}$ and Si-related peaks in XRD and EDX results, respectively.
These results can be investigated and generalized to other specimens.

The prominent Bragg's law as follows:

$$
n \lambda=2 d_{h k l} \sin \theta,
$$

where $n$ is the order of reflection, which may be any integer $(1,2,3, \ldots), \lambda$ the X-ray wavelength, $d_{h k l}$ the inter planar separation for a plane having indices $h, k$ and $l$ and $\theta$ the angle of diffraction for constructive interference. Distance between two adjacent and parallel planes of atoms for a cubic crystal is as follows:

$$
d_{h k l}=a / \sqrt{h^{2}+k^{2}+l^{2}} .
$$

Here $a$ is the lattice parameter.

From these two recent equations, it is obvious that there is an inverse relationship between $\theta$ and $d_{h k l}$. It means that by increasing each one, the other one is decreased. Tensile and compressive strains can increase and decrease the $d_{h k l}$ value; thus, can shift the peaks to the right and left, respectively [37].

According to figure 1, remarkable shifts in XRD patterns of some specimens have been created. This phenomena refer to the amount and type of strain that can be tensile or

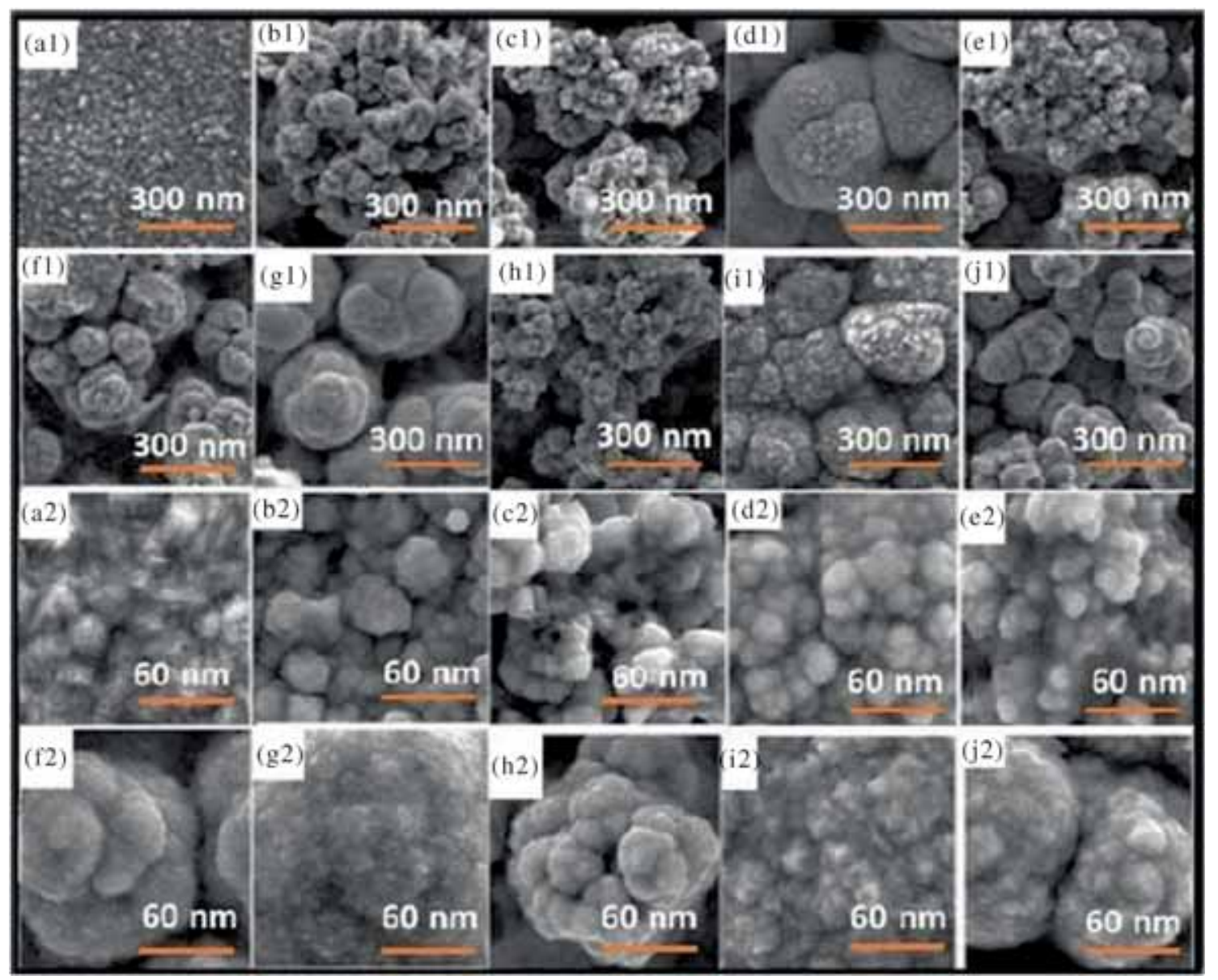

Figure 2. FE-SEM images of coatings, DET: secondary electron, average SEM HV: 15 kV, average work distance: $13.6 \mathrm{~mm}$. 
compressive. $\mathrm{Ni}-\mathrm{Co} / \mathrm{SiO}_{2}$ is a nickel-based nanocomposite. It is known that lattice parameters of nickel and cobalt are about 0.35 and $0.25 \mathrm{~nm}$, respectively. Formation of solid solution between nickel and cobalt because of less amount of lattice parameter of cobalt caused tensile strain in nickel lattice (right shift). However, by adding $\mathrm{SiO}_{2}$ nanoparticles, compressive strain can be made on the coating (left shift). So the amount of cobalt and $\mathrm{SiO}_{2}$ nanoparticles in the coating determined the amount and type of strain. In figure 1, it can be seen that XRD pattern of specimen 12 (Ni-Co alloy coating without $\mathrm{SiO}_{2}$ nanoparticles) has the most shift to the right. By adding $\mathrm{SiO}_{2}$ nanoparticles into the coating (especially in specimens $1,2,3,4,8,9$ and 10), it can be seen that patterns shift to the left. In other specimens (5, 6, 7 and 11) because of heterogeneous distribution of cobalt and $\mathrm{SiO}_{2}$ on the coating all or portion of tensile and compressive strains neutralized each other. Maybe XRD analysis prepared from the zones of coatings which the aggregation of cobalt is much higher than that of $\mathrm{SiO}_{2}$ nanoparticles. So generally, there was low compressive strain in those places of coating; thus, low shift (to left) in the XRD results could be seen.

\subsection{FESEM images, $X$-ray map and EDX analysis of $\mathrm{Ni}-\mathrm{Co} / \mathrm{SiO}_{2}$ nanocomposite coating}

Figure 2 indicates FESEM images of $\mathrm{Ni}-\mathrm{Co} / \mathrm{SiO}_{2}$ nanocomposite coating. To investigate effect of pulse frequency, current density and duty cycle on the morphology of samples, a comparison was done between samples produced in the lowest $(5 \mathrm{~Hz})$ and the highest $(100 \mathrm{~Hz})$ values of pulse frequency. Also, samples with minimum $\left(2 \mathrm{~A} \mathrm{dm}^{-2}\right)$ and maximum $\left(8 \mathrm{~A} \mathrm{dm}^{-2}\right)$ values of current density and duty cycle (minimum $30 \%$ and maximum $60 \%$, respectively) were compared. The reason for these selections was to create the greatest differences between coating morphologies via the most variation range of mentioned parameters.

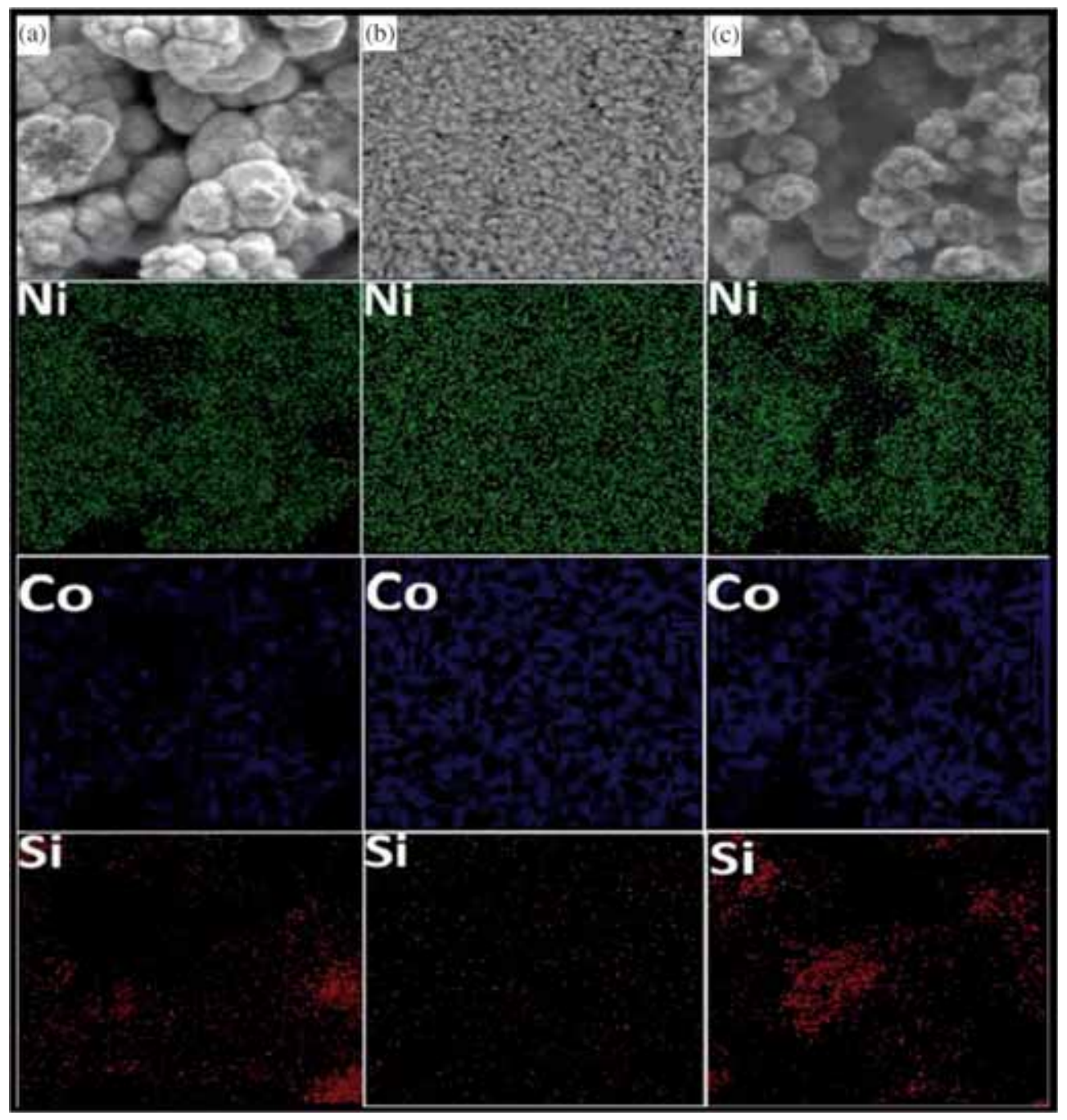

Figure 3. $\mathrm{Ni}-\mathrm{Co} / \mathrm{SiO}_{2}$ nanocomposite coating, $\mathrm{X}$-ray map, $\mathrm{Ni}, \mathrm{Co}$ and $\mathrm{Si}$ distribution, magnification 10000. (a) Pulse current type, current density $6 \mathrm{~A} \mathrm{dm}^{-2}$, pulse frequency $10 \mathrm{~Hz}$, duty cycle $50 \%$, (b) pulse current type, current density $4 \mathrm{~A} \mathrm{dm}^{-2}$, pulse frequency $10 \mathrm{~Hz}$, duty cycle $50 \%$, (c) pulse current type, current density $4 \mathrm{~A} \mathrm{dm}^{-2}$, pulse frequency $25 \mathrm{~Hz}$, duty cycle $50 \%$. 
Also, morphology of samples which have been produced under pulse and direct current electrodeposition methods (conditions, in pulse current method: $4 \mathrm{~A} \mathrm{dm}^{-2}, 10 \mathrm{~Hz}$ and 50\% and in direct current method: $4 \mathrm{~A} \mathrm{dm}^{-2}, 100 \%$, respectively) were compared. So, among these 13 specimens, totally 10 specimens were selected to investigate the surface morphology. Here, samples have been introduced from a1 to j2. It should be mentioned that samples with same english alphabet belong to one sample. For example, a1 and a2 are related to one. Sample indexes 1 and 2 refer to the magnification of 10,000 and 50,000, respectively.

As a result of long $T_{\mathrm{ON}}$ and $T_{\mathrm{OFF}}$, the discharge rate in low pulse frequency ( $\mathrm{c} 1$ and $\mathrm{c} 2$ images, conditions: $4 \mathrm{~A} \mathrm{dm}^{-2}$, $5 \mathrm{~Hz}$ and $50 \%$ ) is more than that of high pulse frequency (d1 and $\mathrm{d} 2$ images, conditions: $4 \mathrm{~A} \mathrm{dm}^{-2}, 100 \mathrm{~Hz}$ and $50 \%$ ). At high current densities (h1 and h2 images, conditions: $8 \mathrm{~A} \mathrm{dm}^{-2}, 10 \mathrm{~Hz}$ and $50 \%$ ) and high duty cycles (e1 and e2 images, conditions: $4 \mathrm{~A} \mathrm{dm}^{-2}, 10 \mathrm{~Hz}$ and 60\%), the discharge rate increases. Conversely, at low current densities ( $\mathrm{g} 1$ and g2 images, conditions: $2 \mathrm{~A} \mathrm{dm}^{-2}, 10 \mathrm{~Hz}$ and $50 \%$ ) and low duty cycles (f1 and $\mathrm{f} 2$ images, conditions: $4 \mathrm{~A} \mathrm{dm}^{-2}, 10 \mathrm{~Hz}$ and 30\%), the rate is reduced. Therefore, in low discharge rates (like low solidification rates), the surface morphology is ordered, smooth and gross globular, while in high discharge rates (like high solidification rates), the surface morphology is disordered, rough and fine globular. FESEM images of $\mathrm{Ni}-\mathrm{Co} / \mathrm{SiO}_{2}$ nanocomposite coatings that were prepared by pulse current ( $\mathrm{a} 1$ and $\mathrm{a} 2$ images, conditions: $4 \mathrm{~A} \mathrm{dm}^{-2}, 19 \mathrm{~Hz}$ and 50\%) and direct current (b1 and b2 images, conditions: $4 \mathrm{~A} \mathrm{dm}^{-2}$ and 100\%) were shown. It can be seen that in pulse current method, surface morphology is smoother and more ordered, yet in direct current method, surface structure is rough, disordered and gross globular. In direct current method, discharge rate is more than that of produced in pulse current method. As a result, in pulse current method, the surface morphology is same as the low solidification rate structure. In direct current method, however, the surface morphology is similar to high solidification rate structure, yet it is rough and disordered.

By comparing FESEM images of Ni-Co alloy coatings prepared by pulse current (i1 and i2 images, conditions: $4 \mathrm{~A} \mathrm{dm}^{-2}, 10 \mathrm{~Hz}$ and 50\%) and direct current (j1 and j2 images, conditions: $4 \mathrm{~A} \mathrm{dm}^{-2}$ and 100\%), due to the high discharge rate of direct current, the surface morphology is
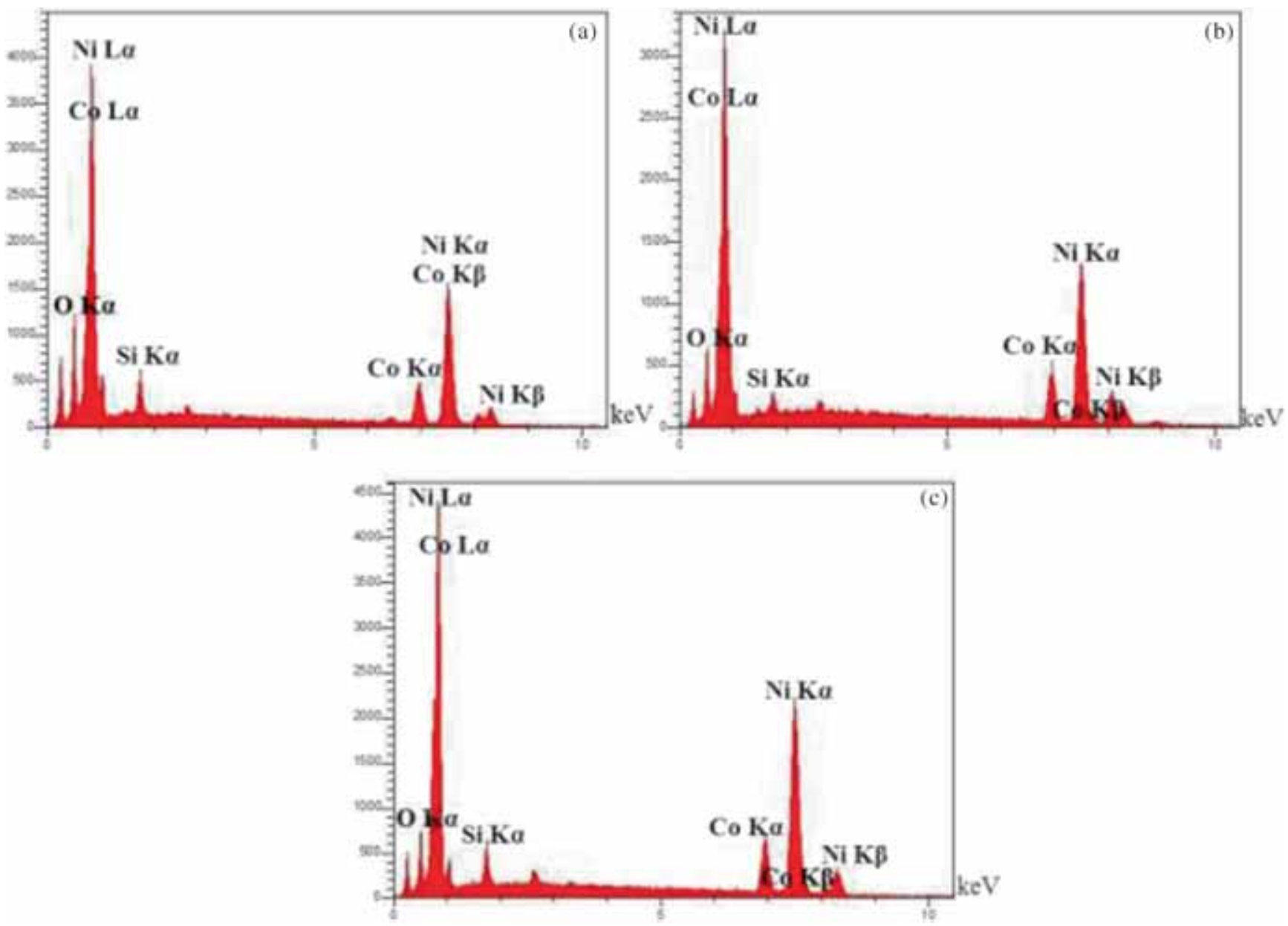

Figure 4. EDX analysis of $\mathrm{Ni}-\mathrm{Co} / \mathrm{SiO}_{2}$ nanocomposite coating; (a) pulse current type, current density $6 \mathrm{~A} \mathrm{dm}^{-2}$, pulse frequency $10 \mathrm{~Hz}$, duty cycle $50 \%$, (b) pulse current type, current density $4 \mathrm{~A} \mathrm{dm}^{-2}$, pulse frequency $10 \mathrm{~Hz}$, duty cycle $50 \%$, (c) pulse current type, current density $4 \mathrm{~A} \mathrm{dm}^{-2}$, pulse frequency $25 \mathrm{~Hz}$, duty cycle $50 \%$. 
rough, disordered and gross globular. Nonetheless, in pulse current surface, the morphology is smoother, more ordered and fine globular. According to figure 2, it is obvious that surface morphologies are almost similar in some samples like b1: direct current, c1: minimum pulse frequency and e1: maximum duty cycle. This is because, under these conditions precipitation rate of coatings was high. In these situations like high solidification rate, the surface morphology was rougher, more disordered and gross globular.

Also, there is no major difference between $\mathrm{f} 1$ : minimum duty cycle and e1: maximum duty cycle. Actually, duty cycle changed from 30 to $60 \%$. It means that duty cycle has been redoubled. Current density (variation from 2 to $8 \mathrm{~A} \mathrm{dm}^{-2}$ ) has been quadruplicated. Maximum value of pulse frequency $(100 \mathrm{~Hz})$ is 20 times more than the minimum value $(5 \mathrm{~Hz})$. It can be said that variation of duty cycle in comparison to other electrodeposition parameters was so less. This is the reason for low change in surface morphology of coating via variation in duty cycle.

Figure 3 delineates the X-ray map (which attached to FESEM) of three $\mathrm{Ni}-\mathrm{Co} / \mathrm{SiO}_{2}$ nanocomposite coating specimens where $\mathrm{Ni}, \mathrm{Co}$ and $\mathrm{Si}$ distributions are clearly seen in the matrix. Ni and $\mathrm{Co}$ are distributed homogeneously in prepared Ni-Co alloy. Also, it can be seen that $\mathrm{Si}$ (refer to $\mathrm{SiO}_{2}$

Table 3. EDX analysis of wt $\%$ of $\mathrm{Ni}, \mathrm{Co}$ and $\mathrm{Si}$ elements and $\mathrm{SiO}_{2}$ nanoparticles in $\mathrm{Ni}-\mathrm{Co} / \mathrm{SiO}_{2}$ nanocomposite coating. (a) Pulse current type, current density $6 \mathrm{~A} \mathrm{dm}^{-2}$, pulse frequency $10 \mathrm{~Hz}$, duty cycle $50 \%$. (b) Pulse current type, current density $4 \mathrm{~A} \mathrm{dm}^{-2}$, pulse frequency $10 \mathrm{~Hz}$, duty cycle $50 \%$. (c) Pulse current type, current density $4 \mathrm{~A} \mathrm{dm}^{-2}$, pulse frequency $25 \mathrm{~Hz}$, duty cycle $50 \%$.

$\begin{array}{lllll}\text { Material/specimens } & \mathrm{Ni}(\mathrm{wt} \%) & \mathrm{Co}(\mathrm{wt} \%) & \mathrm{Si}(\mathrm{wt} \%) & \mathrm{SiO}_{2}(\mathrm{wt} \%)\end{array}$

\begin{tabular}{lllll}
\hline $\mathrm{a}$ & 67.68 & 14.98 & 2.78 & 6.65 \\
$\mathrm{~b}$ & 74.67 & 12.76 & 1.49 & 3.19 \\
$\mathrm{c}$ & 76.12 & 15.80 & 1.91 & 4.08 \\
\hline
\end{tabular}

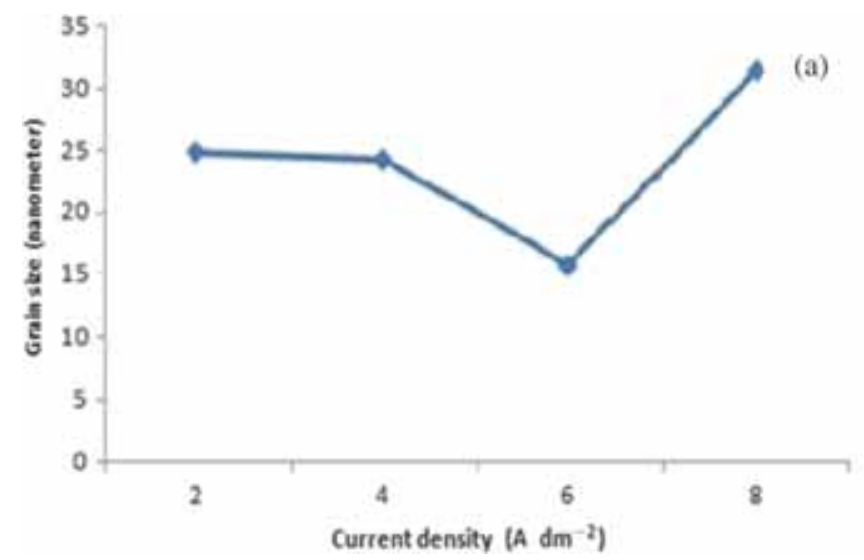

nanoparticles) is distributed in matrix (Ni-Co alloy) and this confirms that $\mathrm{Ni}-\mathrm{Co} / \mathrm{SiO}_{2}$ nanocomposite coating has been prepared successfully. Figure 4 displays EDX analysis (which attached to FESEM) of three $\mathrm{Ni}-\mathrm{Co} / \mathrm{SiO}_{2}$ nanocomposite coating specimens. This figure represents that presence of $\mathrm{Ni}, \mathrm{Co}, \mathrm{O}$ and $\mathrm{Si}$ elements in the coating caused the formation of $\mathrm{Ni}-\mathrm{Co} / \mathrm{SiO}_{2}$ nanocomposite coating. Table 3 shows the EDX analysis of the wt\% of Ni, Co and $\mathrm{Si}$ elements and $\mathrm{SiO}_{2}$ nanoparticles in $\mathrm{Ni}-\mathrm{Co} / \mathrm{SiO}_{2}$ nanocomposite coating.

\subsection{Effect of average current density on the grain size and microhardness of $\mathrm{Ni}-\mathrm{Co} / \mathrm{SiO}_{2}$ nanocomposite coating}

Figure 5a shows grain size variations of $\mathrm{Ni}-\mathrm{Co} / \mathrm{SiO}_{2}$ nanocomposite coating by increasing (average) the current density. By increasing the average current density from 2 to 6 $\left(A \mathrm{dm}^{-2}\right)$, grain size decreased, but with further increasing to $8\left(\mathrm{~A} \mathrm{dm}^{-2}\right)$, the grain size increased. Through increasing the nanoparticles in the coating, grain size decreased since entrapped nanoparticles have more influence on the grain size of $\mathrm{Ni}-\mathrm{Co} / \mathrm{SiO}_{2}$ nanocomposite coating. Increasing the amount of these nanoparticles in the coating, decreases the grain size, because these nanoparticles could decrease grain boundary mobility and prevent grain growth, and also nanoparticles are suitable places for heterogeneous nucleation [10].

For low-average current density, electrodeposition process did not complete properly, because attraction forces between the surrounded nanoparticles by positive metallic ions and cathode surface were weak. But in high current density, chances for reduction of independent positive ions $\left(\mathrm{Ni}^{2+}\right.$ and $\mathrm{Co}^{2+}$ ) were more than nanoparticles (with cationic cloud around them). So, the nanoparticles entrapment was limited. Therefore, there was an optimum average current density value.

Figure $5 \mathrm{~b}$ illustrates the variations of microhardness of nanocomposite by increasing the (average) current density. As can be seen with the increase in the average current

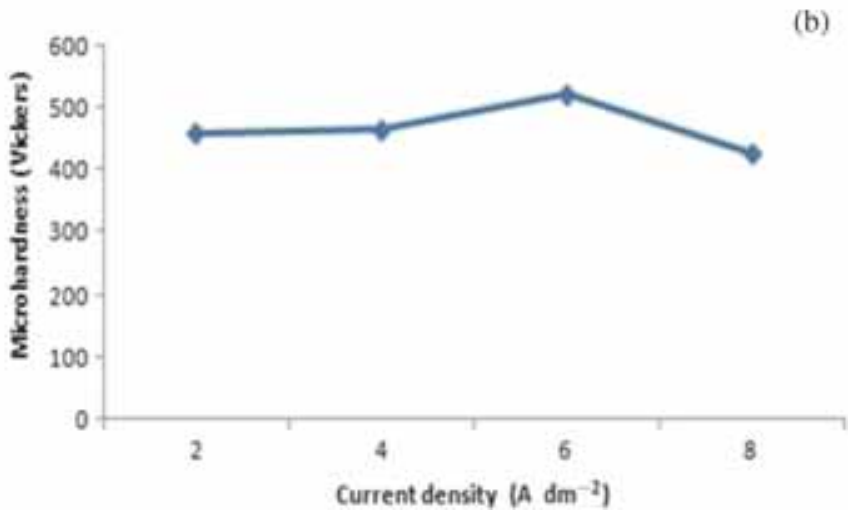

Figure 5. (a) Effect of current density variations on the $\mathrm{Ni}-\mathrm{Co} / \mathrm{SiO}_{2}$ nanocomposite coating grain size, pulse frequency $10 \mathrm{~Hz}$, duty cycle $50 \%$. (b) $\mathrm{Ni}-\mathrm{Co} / \mathrm{SiO}_{2}$ nanocomposite coating microhardness variations with current density variations in pulse frequency of $10 \mathrm{~Hz}$ and duty cycle of $50 \%$. 
density from 2 to $6\left(\mathrm{~A} \mathrm{dm}^{-2}\right)$, the microhardness coating increased, but by further increasing the average current density, it decreased. In low current density, because of the low electrical charge, the attraction between nanoparticles surrounded by positive ion clouds and cathode is low. So the hydrodynamic forces which were caused by electrolyte agitation could dislodge nanoparticles, which were wickedly attracted by the substrate from the cathode surface. That is why nanoparticles content in the coating decreased and consequently, microhardness is reduced. By increasing the average current density to $6\left(\mathrm{~A} \mathrm{dm}^{-2}\right)$, the attraction force between nanoparticles (which were surrounded by cationic cloud) and cathode increased. Consequently, the amount of nanoparticles in the coating increased and thereby the microhardness has been increased. However, by further increasing the average current density to $8\left(\mathrm{~A} \mathrm{dm}^{-2}\right)$, independent positive nickel and cobalt ions were attracted to the substrate more than nanoparticles (surrounded by positive ion cloud). Also, the number of nanoparticles surrounded by positive ion cloud in electrolyte is decreased, subsequently amount of nanoparticles in the coating decreased which led to the reduction of microhardness.

Such as the other research [6] in manufacturing another nanocomposite coating, it can be concluded that optimum average current density for preparing $\mathrm{Ni}-\mathrm{Co} / \mathrm{SiO}_{2}$ nanocomposite coating was $6\left(\mathrm{~A} \mathrm{dm}^{-2}\right)$.

\subsection{Effect of pulse frequency on the grain size and microhardness of $\mathrm{Ni}-\mathrm{Co} / \mathrm{SiO}_{2}$ nanocomposite coating}

Figure 6a shows variation in grain size of $\mathrm{Ni}-\mathrm{Co} / \mathrm{SiO}_{2}$ nanocomposite coating by increasing pulse frequency. In direct current method, the current is always on, the process is fast and mostly positive metallic ions are reduced. On the contrary, the process is slower in pulse current method due to the presence of $T_{\mathrm{ON}}$ and $T_{\mathrm{OFF}}$. In the OFF times, there were more chances for nanoparticles to be surrounded by positive ion clouds and then reach the cathode surface using agitation forces and finally in ON times, they can be discharged there. In low pulse frequencies, $T_{\mathrm{OFF}}$ and $T_{\mathrm{ON}}$ are so high. Because of very high $T_{\mathrm{OFF}}$, attraction force between surrounded nanoparticles and cathode were so weak. Also because of very high $T_{\mathrm{ON}}$, independent positive metallic ions were discharged much faster than surrounded nanoparticles. So in low pulse frequencies, grain size was increased. By increasing the pulse frequency to an optimum value ( $25 \mathrm{~Hz}$ ), because of $T_{\mathrm{ON}}$ and $T_{\mathrm{OFF}}$ decrease, the amount of nanoparticles in the coating increased, thereby grain size reduced.

In high pulse frequencies, $T_{\mathrm{ON}}$ and $T_{\mathrm{OFF}}$ were very short and the chance for $\mathrm{SiO}_{2}$ nanoparticles to be surrounded by positive ions is low. Accordingly, for low (less than $25 \mathrm{~Hz}$ ) and high (more than $25 \mathrm{~Hz}$ ) pulse frequencies, the amount of nanoparticles in the coating were decreased, thereby grain size of coating was increased.

Figure $6 \mathrm{~b}$ represents the influence of pulse frequency on the $\mathrm{Ni}-\mathrm{Co} / \mathrm{SiO}_{2}$ nanocomposite coating microhardness. As it is shown, by increasing the pulse frequency from 5 to $25 \mathrm{~Hz}$, microhardness increased, but by further increasing from 25 to $100 \mathrm{~Hz}$, it decreased. In low pulse frequency, $T_{\mathrm{ON}}$ and $T_{\mathrm{OFF}}$ are too long and hydrodynamic forces could dislodge nanoparticles surrounded by positive ion cloud from the cathode surface, hence, the content of nanoparticles in the coating decreased, so microhardness of sample reduced.

On the other hand, $T_{\mathrm{OFF}}$ was more than optimum value and the amount of nanoparticles surrounded by positive ion cloud increased in the electrolyte, but since $T_{\mathrm{OFF}}$ was too long, they could not be attracted by substrate. $T_{\mathrm{ON}}$ was also very long and the metal positive ions were quickly attracted to the substrate; thus, amount of nanoparticles in the coating were decreased, followed by decreasing the microhardness of samples. By increasing the pulse frequency this problem can be solved, it means that $T_{\mathrm{ON}}$ and $T_{\mathrm{OFF}}$ can get closer to the optimum value, hence, the amount of nanoparticles in the coating were increased. Nonetheless, with further increase in the pulse frequency from 25 to $100 \mathrm{~Hz}, T_{\mathrm{ON}}$ and $T_{\mathrm{OFF}}$ become short. $T_{\mathrm{OFF}}$ for nanoparticles surrounded by metal positive ion cloud was less than optimum value, thereby amount of nanoparticles in the coating and microhardness were decreased. As mentioned in other researches [11,22],
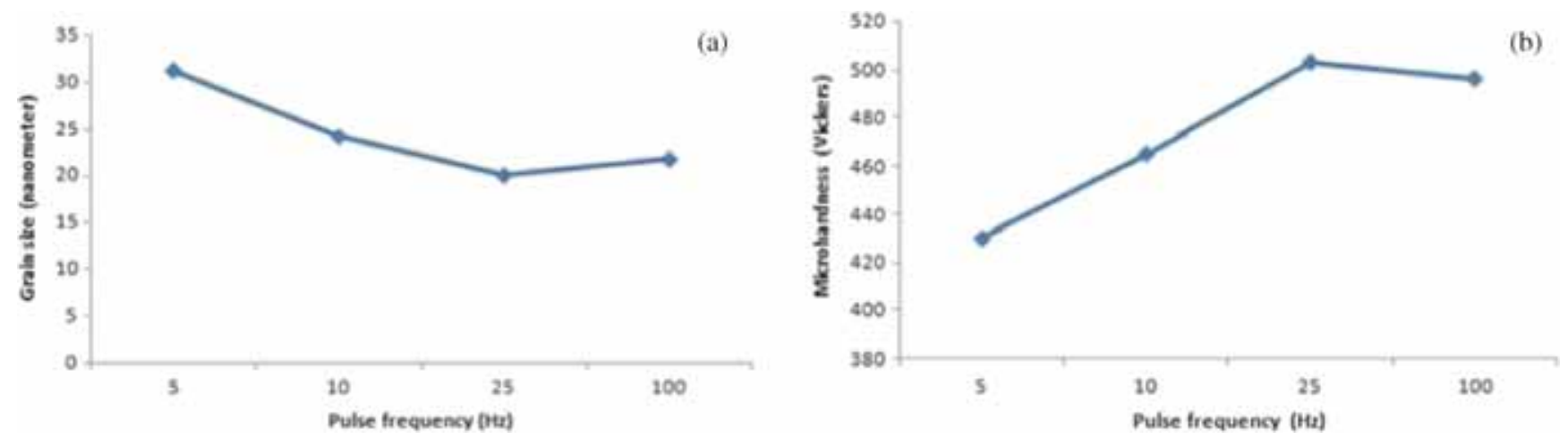

Figure 6. (a) $\mathrm{Ni}-\mathrm{Co} / \mathrm{SiO}_{2}$ nanocomposite coating grain size variation with increasing pulse frequency, current density $4 \mathrm{~A}$ dm ${ }^{-2}$, duty cycle $50 \%$. (b) Influence of pulse frequency on the $\mathrm{Ni}-\mathrm{Co} / \mathrm{SiO}_{2}$ nanocomposite coating microhardness in current density of $4 \mathrm{~A} \mathrm{dm}^{-2}$ and duty cycle of $50 \%$. 
there is an optimum value for pulse frequency in preparing other nanocomposite coatings. In this work, for preparing $\mathrm{Ni}-\mathrm{Co} / \mathrm{SiO}_{2}$ nanocomposite coating, optimum value of pulse frequency (to get maximum microhardness) was $25 \mathrm{~Hz}$.

\subsection{Effect of duty cycle on the grain size and microhardness of $\mathrm{Ni}-\mathrm{Co} / \mathrm{SiO}_{2}$ nanocomposite coating}

Figure 7 a shows variations in grain size of $\mathrm{Ni}-\mathrm{Co} / \mathrm{SiO}_{2}$ nanocomposite coating by increasing the duty cycle. In low duty cycle values (less than $50 \%$ ), $T_{\mathrm{OFF}}$ is very long; on the contrary, $T_{\mathrm{ON}}$ is so short and the conditions are the same as those of in low current density. However, in high duty cycle values (more than $50 \%$ ), $T_{\mathrm{OFF}}$ is very short, but $T_{\mathrm{ON}}$ is very long and the conditions are the same as high current density values. Moreover, it can be seen that in duty cycle of $100 \%$ (direct current electrodeposition method), grain size of $\mathrm{Ni}-\mathrm{Co} / \mathrm{SiO}_{2}$ nanocomposite coating is greater than that of in pulse current electrodeposition method.

It is expected that by reducing the duty cycle and increasing the amount of nanoparticles in the coating, grain size of nanocomposite coating was decreased [5].

Figure $7 \mathrm{~b}$ shows the $\mathrm{Ni}-\mathrm{Co} / \mathrm{SiO}_{2}$ nanocomposite coating microhardness changes caused by duty cycle variations. As can be observed, in low duty cycles, $T_{\mathrm{OFF}}$ is too long, attraction force between substrate and nanoparticles surrounded by metal positive ion cloud is so weak that the hydrodynamic
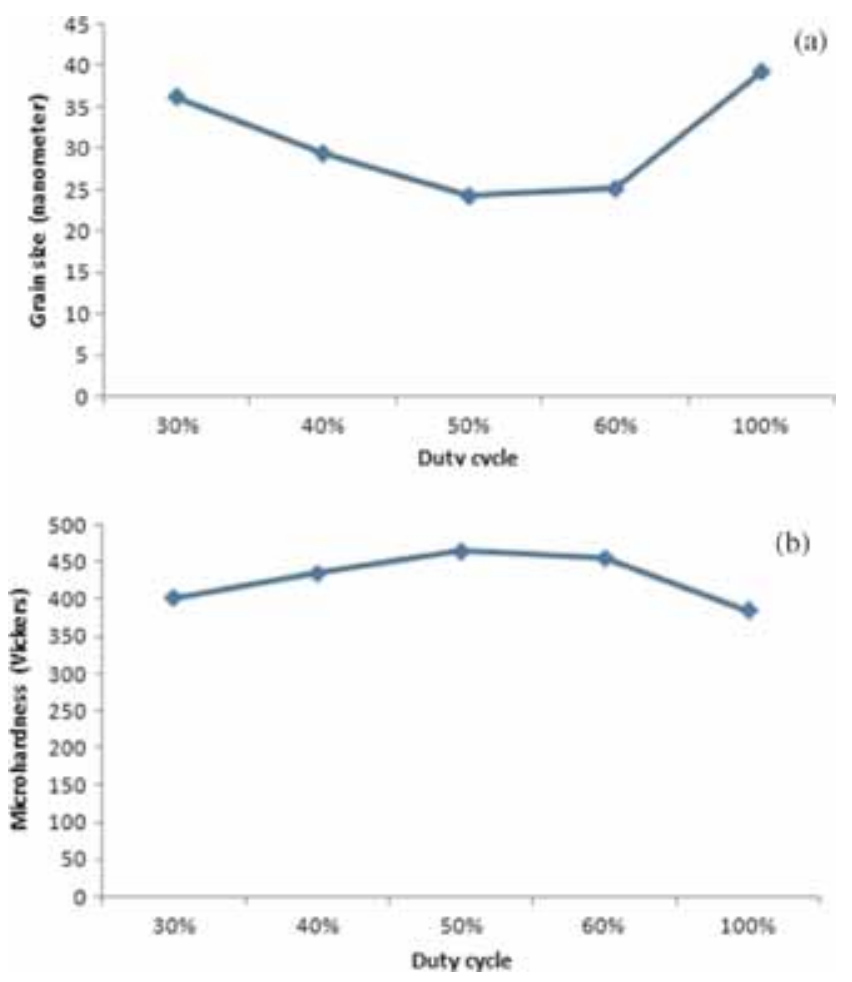

Figure 7. (a) The influence of duty cycle percent on the $\mathrm{Ni}-\mathrm{Co} / \mathrm{SiO}_{2}$ nanocomposite coating grain size, current density $4 \mathrm{~A} \mathrm{dm}^{-2}$, pulse frequency $10 \mathrm{~Hz}$. (b) The effect of duty cycle variations on the $\mathrm{Ni}-$ $\mathrm{Co} / \mathrm{SiO}_{2}$ nanocomposite coating microhardness in current density of $4 \mathrm{~A} \mathrm{dm}^{-2}$ and pulse frequency of $10 \mathrm{~Hz}$. forces could dislodge the nanoparticles from the substrate surface. Consequently, reducing the amount of nanoparticles in the coating caused the reduction in microhardness.

By increasing the duty cycle to $50 \%$, because $T_{\mathrm{OFF}}$ is shorter, mentioned problems disappeared. So, the amount of nanoparticles in the coating and microhardness were increased. However, by further increasing the duty cycle to $100 \%$ (DC method), $T_{\text {ON }}$ becames so long, and mostly metal positive ions were more fortunate to achieve the cathode. Also, the quantity of nanoparticles surrounded by metal positive ion cloud declined in the solution. Therefore, the amount of nanoparticles in the coating and the microhardness were decreased. Thus, duty cycle has an optimum value [14,22], which for preparing $\mathrm{Ni}-\mathrm{Co} / \mathrm{SiO}_{2}$ nanocomposite was $50 \%$. As can be seen, coating microhardness in direct current method (100\% of duty cycle) was less than that of in pulse current method.

Figure 8 provides a comparative image between the grain sizes of different kinds of coating. It can be seen that nanocomposite coating has a finer grain size than alloy coating (since nanocomposite coating involves nanoparticle reinforcements) and in direct current method greater grain sizes can be reached.

In figure 9, the microhardness of some coatings prepared by pulse and direct methods and steel substrate are compared. Results showed that nanocomposite coating had better microhardness than alloy coating and this microhardness was higher when pulse current method was used. It can be explained by the fact that in pulse method, there are OFF times and ON times. Perhaps because of OFF times and thereby less rate of process, there were more chance and time for nanoparticles which are surrounded by positive ions $\left(\mathrm{Ni}^{2+}\right.$ and $\left.\mathrm{Co}^{2+}\right)$ and then move to the cathode surface and

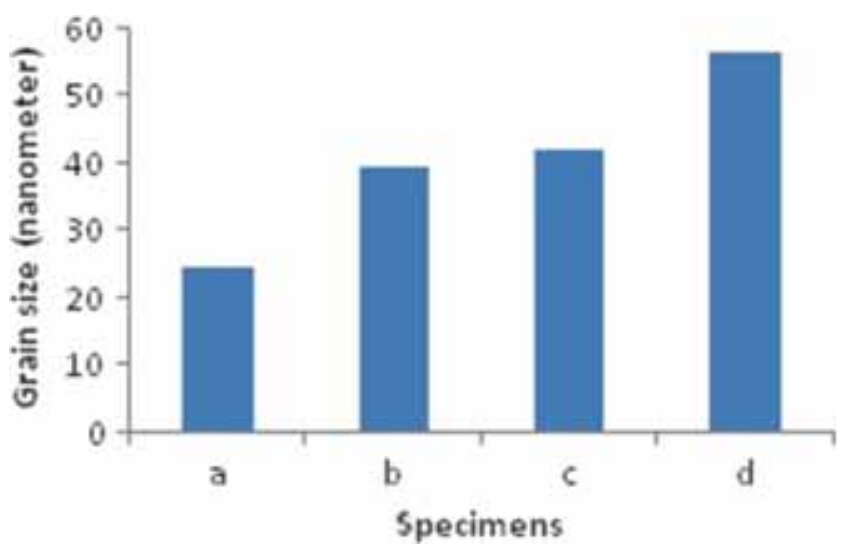

Figure 8. Comparison of grain size between (a) $\mathrm{Ni}-\mathrm{Co} / \mathrm{SiO}_{2}$ nanocomposite coating prepared in pulse current electrodeposition method, current density of $4 \mathrm{~A} \mathrm{dm}^{-2}$, pulse frequency of $10 \mathrm{~Hz}$, duty cycle of $50 \%$. (b) $\mathrm{Ni}-\mathrm{Co} / \mathrm{SiO}_{2}$ nanocomposite coating prepared in direct current electrodeposition method, current density of $4 \mathrm{~A} \mathrm{dm}^{-2}$. (c) $\mathrm{Ni}-\mathrm{Co}$ alloy coating prepared in pulse current electrodeposition method, current density of $4 \mathrm{~A} \mathrm{dm}^{-2}$, pulse frequency of $10 \mathrm{~Hz}$, duty cycle of $50 \%$. (d) Ni-Co alloy coating prepared in direct current electrodeposition method, current density of $4 \mathrm{~A} \mathrm{dm}^{-2}$. 


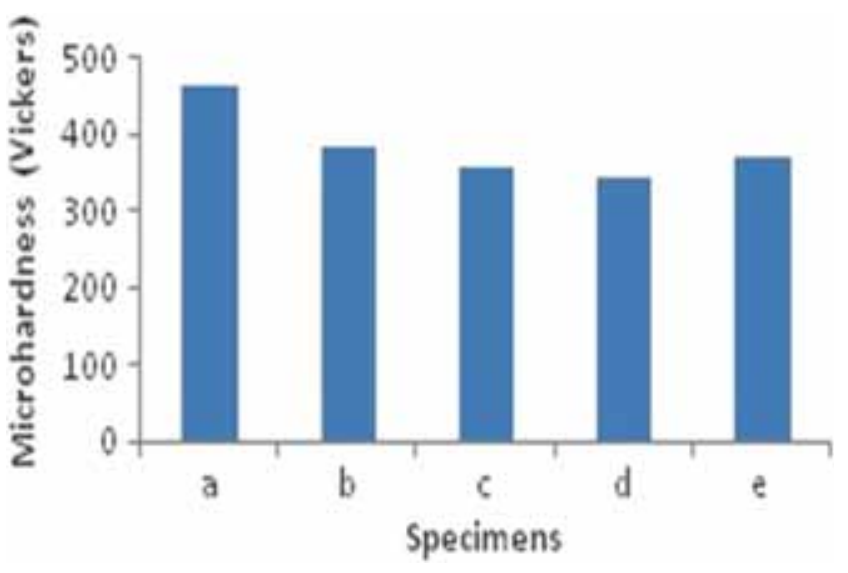

Figure 9. Comparison of microhardness between (a) $\mathrm{Ni}-\mathrm{Co} / \mathrm{SiO}_{2}$ nanocomposite coating prepared in pulse current electrodeposition method, current density of $4 \mathrm{~A} \mathrm{dm}^{-2}$, pulse frequency of $10 \mathrm{~Hz}$, duty cycle of $50 \%$. (b) $\mathrm{Ni}-\mathrm{Co} / \mathrm{SiO}_{2}$ nanocomposite coating prepared in direct current electrodeposition method, current density of $4 \mathrm{~A} \mathrm{dm}^{-2}$. (c) Ni-Co alloy coating prepared in pulse current electrodeposition method, current density of $4 \mathrm{~A} \mathrm{dm}^{-2}$, pulse frequency of $10 \mathrm{~Hz}$, duty cycle of $50 \%$. (d) Ni-Co alloy coating prepared in direct current electrodeposition method, current density of $4 \mathrm{~A} \mathrm{dm}^{-2}$. (e) Steel substrate.

would be reduced there. But in direct current method, the rate of coating increased. So, there was more chance for $\mathrm{Ni}^{2+}$ and $\mathrm{Co}^{2+}$ to be reduced on the cathode surface, so the amount of surrounded nanoparticles by positive ions was decreased and consequently, the amount of entrapped nanoparticles in the coating lessened and thereby microhardness was reduced.

Finally in table 3, elemental distribution and analysis for three samples which have maximum microhardness and minimum grain size have been indicated. Here, samples a, b and c are samples 3, 2 and 6 in table 2, respectively.

\section{Conclusions}

In general, in this study, $\mathrm{Ni}-\mathrm{Co} / \mathrm{SiO}_{2}$ nanocomposite coating was prepared by electrodeposition method for the first time. Effects of average current density, pulse frequency and duty cycle on the microhardness, grain size and surface morphology of the coating were also investigated. The microhardness, grain size and surface morphology of $\mathrm{Ni}-\mathrm{Co}$ alloy and $\mathrm{Ni}-\mathrm{Co} / \mathrm{SiO}_{2}$ nanocomposite coating that were prepared in the DC and PC methods have also been compared.

In high discharge rates (high current density, duty cycle, low pulse frequency and DC method), the surface morphology was rough, disordered and gross globular, conversely in low discharge rates (low current density, duty cycle, high pulse frequency and PC method), it was smoother, more ordered and fine globular.

Results indicated that in DC method, grain size of coating was higher than that of in the PC method. Also, grain size in $\mathrm{Ni}-\mathrm{Co} / \mathrm{SiO}_{2}$ nanocomposite coating was less than that in $\mathrm{Ni}-\mathrm{Co}$ alloy coating.
Additionally, the microhardness of coatings produced by PC method was more than that of in DC method. Furthermore, the microhardness of $\mathrm{Ni}-\mathrm{Co} / \mathrm{SiO}_{2}$ nanocomposite coating was more than $\mathrm{Ni}-\mathrm{Co}$ alloy coating.

For average current density, duty cycle and pulse frequency, there were optimum values $\left(6 \mathrm{~A} \mathrm{dm}^{-2}, 50 \%\right.$ and $25 \mathrm{~Hz}$, respectively) and any deviation from those optimum values led to increase in the grain size, while decrease in the microhardness.

It was concluded that $\mathrm{SiO}_{2}$ nanoparticles entrapped in the coating, influenced on the grain size and microhardness of $\mathrm{Ni}-\mathrm{Co} / \mathrm{SiO}_{2}$ nanocomposite coating. It means that when the amount of nanoparticles in the coating increased, the coating grain size decreased but microhardness increased.

\section{Acknowledgement}

We are thankful to the Advanced Materials and Nanotechnology Research Laboratory, Faculty of Materials Science and Engineering, K N Toosi University of Technology, for supporting this work.

\section{References}

[1] Gurrappa I and Binder L 2008 Sci. Technol. Adv. Mater. 9 043001

[2] Srivastava M, William Grips V K and Rajam K S 2007 Appl. Surf. Sci. 2533814

[3] Gomes A, Pereira I, Fernández B and Pereiro R 2011 Electrodeposition of metal matrix nanocomposites: improvement of the chemical characterization techniques, in Advances in nanocomposites-synthesis, characterization and industrial applications (ed) Boreddy Reddy ISBN: 978-953-307-165-7, InTech

[4] Devaraj G et al 1990 Mater. Chem. Phys. 25439

[5] Yang Y and Cheng Y F 2013 Surf. Coat. Technol. 216282

[6] Baghery P, Farzam M, Mousavi A B and Hosseini M 2010 Surf. Coat. Technol. 2043804

[7] Vaezi M R, Ssadrnezhaad S K and Nikzad L 2008 Colloids Surf. A 315176

[8] Shahri Z and Allahkaram S R 2012 Iranian J. Mater. Sci. Eng. 91

[9] Yao Y, Yao S, Zhang L and Wang H 2007 Mater. Lett. 6167

[10] Karbasi M, Yazdian N and Vahidian A 2012 Surf. Coat. Technol. 207587

[11] Lajevardi S A and Shahrabi T 2010 Appl. Surf. Sci. 2566775

[12] Singh D K and Singh V B 2012 Mater. Sci. Eng. A 532493

[13] Pouladi S, Shariat M H and Bahrololoom M E 2012 Surf. Coat. Technol. 21333

[14] Sajjadnejad M, Mozafari A, Omidvar H and Javanbakht M 2014 Appl. Surf. Sci. 3001

[15] Ozkan S et al 2013 Surf. Coat. Technol. 232734

[16] Arab Juneghani M, Farzam M and Zohdirad H 2013 Trans. Nonferrous Met. Soc. China 231993

[17] Eslami M, Golestani-Fard F, Saghafian H and Robin A 2014 Mater. Des. 58557 
[18] Chang L M, An M Z, Guo H F and Shi S Y 2006 Appl. Surf. Sci. 2532132

[19] Bahadormanesh B and Dolati A 2010 J. Alloys Compnd. 504514

[20] Arunsunai Kumar K, Paruthimal Kalaignan G and Muralidharan V S 2013 Ceram. Int. 392827

[21] Sen R, Das S and Das K 2011 Mater. Charact. 62257

[22] Zarghami V and Ghorbani M 2014 J. Alloys Compnd. 598236

[23] Eslami M, Saghafian H, Golestani-Fard F and Robin A 2014 Appl. Surf. Sci. 300129

[24] Ikram Ul Haq et al 2013 Surf. Coat. Technol. 235691

[25] Bakhit B and Akbari A 2013 J. Alloys Compnd. 56092

[26] Wang J-L et al 2010 Trans. Nonferrous Met. Soc. China 20 839

[27] Rostami M et al 2013 Appl. Surf. Sci. 265369

[28] Zhang H-J et al 2013 Trans. Nonferrous Met. Soc. China 23 2011
[29] Zhou Y-B et al 2010 Trans. Nonferrous Met. Soc. China 20 104

[30] Lei Shi et al 2006 Appl. Surf. Sci. 2523591

[31] Zhou Y-B and Ding Yuan-Zhu 2007 Trans. Nonferrous Met. Soc. China 17925

[32] Lekka M et al 2011 Surf. Coat. Technol. 2053438

[33] Abdel Aal A, El-Sheikh S M and Ahmed Y M Z 2009 Mater. Res. Bull. 44151

[34] Kilic F, Gul H, Aslan S, Alp A and Akbulut H 2013 Colloids Surf. A 41953

[35] Ranjith B and Paruthimal Kalaignan G 2010 Appl. Surf. Sci. 25742

[36] Wang Junli, Xu Ruidong and Zhang Yuzhi 2012 J. Rare Earth. 3043

[37] Golestanifard F, Bahrevar M A and Salahi E 2013 Materials characterization and analysis methods (Iran: Central Publication of Iran University of Science and Technology) (in Persian) 